\title{
ABORDAGENS NORMATIVAS E DESCRITIVAS ÀS NOTAS DO TRADUTOR DOS ANOS 1960 ATÉ O PRESENTE: EXCERTOS DE UMA REVISÃO BIBLIOGRÁFICA
}

\author{
NORMATIVE AND DESCRIPTIVE APPROACHES TO TRANSLATOR'S NOTES \\ FROM THE '6OS UNTIL NOWADAYS: EXCERPTS OF A BIBLIOGRAPHIC \\ REVIEW
}

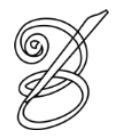 \\ Pablo CARDELLINO SOTO ${ }^{1}$ \\ Doutorando em Estudos da Tradução \\ Programa de Pós-Graduação em Estudos da Tradução (PGET) \\ Universidade Federal de Santa Catarina (UFSC) \\ Florianópolis, Santa Catarina, Brasil \\ pablocardellino@gmail.com
}

Resumo: Segundo Genette, os tradutores acrescentam notas a suas traduções desde a Idade Média (2009, p. 282), mas ao longo da história elas foram muito negligenciadas pelos estudiosos da tradução. No século XX, na esteira do desenvolvimento do pensamento sobre tradução, receberam mais atenção, em geral em artigos e como parte de trabalhos de maior abrangência, mas com poucos esforços de fôlego. As abordagens são principalmente normativas - tanto as que se configuram como balizas para o processo de tomada de decisão dos tradutores quanto as que, no campo da crítica, buscam dar subsídios ao julgamento das notas dos tradutores -, mas há também as abordagens de cunho descritivo. Nesta comunicação, comentaremos algumas dessas contribuições observando suas relações com a história recente de surgimento da disciplina dos Estudos da Tradução.

Palavras-chave: Nota do Tradutor; História da teoria da tradução; Formação de tradutores; Crítica da tradução; Estudos descritivos da tradução.

Abstract:According to Genette, translators add notes to their translations since the Middle Ages (2009, p. 282). However, they were extremely neglected by translation experts throughout history. In the $20^{\text {th }}$ century, in the wake of development of translation thinking, translator's notes have received more attention, broadly in papers, and as part of more comprehensive works, but with low impact. The approaches are mainly normative - both the ones that are fundamental to the translator's process of decision-making and the ones that aid the analysis of translator's notes in the critique field. There are also descriptive approaches, which will be commented in relation to the recent history of the advent of the Translation Studies as a discipline.

Key-words: translator's notes; history of translation theory; translator's education; translation criticism; Descriptive Translation Studies

s Notas do Tradutor ${ }^{2}$ são um assunto frequente nas conversas entre tradutores, e
costumam despertar posicionamentos apaixonados: alguns são contra, outros a
favor, e não é raro ver discussões em termos de "pode" ou "não pode". Com efeito, para os tradutores, que lidam no dia-a-dia com textos e problemas tradutórios, as notas são um 
recurso disponível e, portanto, uma possibilidade de solução. De fato, meu interesse nas notas como objeto de estudo surgiu durante o meu mestrado (CARDELLINO, 2011), no qual fiz uma tradução comentada, em determinado ponto da qual discuto a possível inserção de uma nota como possibilidade de solução de um problema. O levantamento bibliográfico necessário para essa discussão me mostrou como as N.T. têm sido negligenciadas nos Estudos da Tradução. Alguns silêncios me parecem emblemáticos, como a quase inexistência do assunto na Routledge Encyclopedia of Translation Studies, ou a parcimônia de Lawrence Venuti a respeito no seu estudo sobre invisibilidade do tradutor (VENUTI, 1995). Embora segundo Gérard Genette as notas existam desde a Idade Média, é somente a partir da segunda metade do século XX que algumas contribuições sobre as notas dos tradutores começam a surgir, de forma mais ou menos esporádica, na esteira do desenvolvimento do pensamento sobre tradução que seria marcado pelo surgimento da disciplina dos Estudos da Tradução. Essas contribuições são muito esparsas, fragmentárias e assistemáticas, na maior parte menções feitas quase en passant no escopo de estudos e tratados mais abrangentes sobre tradução, e principalmente de caráter prescritivo.

90 Esse caráter prescritivo dominante é compreensível em abordagens direcionadas para a formação e capacitação de tradutores, para o processo de tomada de decisão e demais fins relacionados com a atividade de traduzir. Dentre estas abordagens, uma importante fonte de informação são os pesquisadores ligados à tradução de textos sagrados, como Eugene Nida, que desde a década de 1960 pesquisa e instrui tradutores a respeito da tradução bíblica.

Em 1964 ele afirma que as N.T. têm duas funções primordiais: "trazer informação que, de um modo geral, poderá ser útil para compreender o contexto histórico e cultural do documento em questão" e "corrigir diferenças linguísticas e culturais, por exemplo (a) explicar costumes contraditórios, (b) identificar objetos físicos ou geográficos desconhecidos, (c) oferecer equivalentes de pesos e medidas, (d) fornecer informação sobre trocadilhos, (e) incluir dados complementares sobre nomes próprios (como fariseus, saduceus, hedomitas)" (NIDA, 1964, p. 238).

Em trabalho posterior, ele e Charles Taber incluem algumas questões estilísticas no rol de possibilidades de uso das notas, mas eles frisam que a nota não pode servir à expressão de um problema deixado sem solução no texto, e sim de alternativa à solução adotada (NIDA \& TABER, 1982).

No Brasil também houve contribuições de caráter prescritivo sobre o uso de N.T. De

CARDELLINO SOTO. Abordagens normativas e descritivas às notas do tradutor dos anos 1960 até o presente: excertos de uma revisão bibliográfica.

Belas Infiéis, v. 4, n.2, p. 89-96, 2015. 
forma semelhante a Nida, Rónai sustenta que as N.T. podem ser usadas quando sua ausência resultaria em um texto pouco claro para os leitores de outra nação (RÓNAI, 1976, p. 65) e também que, inclusive, são desejáveis em obras clássicas, “distantes de nós em tempo, lugar e espírito" (id., ibid.). Porém, ele adverte que "[...] são desaconselhadas em livros de ficção, onde [...] contribuem para quebrar a ilusão" e que "há quem recomende ao tradutor encontrar um jeito para incorporá-las ao texto sem o sobrecarregar" (id., ibid.).

Já na década de 80, Peter Newmark (1987), dirigindo-se a tradutores em formação instrui sobre a forma de fazer acréscimos esclarecedores ou explicativos a uma tradução, sejam dentro do texto, como inserções ou glosas, ou fora dele, como notas de rodapé, de final de capítulo ou de final de livro. Ele estabelece três categorias: os acréscimos de caráter cultural (diferenças entre os âmbitos de circulação do original e da tradução), técnico (relativos ao assunto) ou linguístico (explicando usos inesperados das palavras). Baseado na teoria da linguagem de Jakobson, Newmark esclarece que em textos expressivos esse tipo de acréscimos somente deveria ser feito em nota, enquanto em textos vocativos deveria ser feito apenas dentro dele.

Através de uma abordagem linguística e cultural, M. ${ }^{a}$ Luisa Donaire se detém sobre o fato de as N.T. revelarem questões relacionadas com o processo tradutório. A pesquisadora entende que o tradutor se relaciona com o texto original em "duas fases sucessivas: uma de desconstrução, de distanciamento, e uma fase de reconstrução, de apropriação, que se tornam evidentes [...] nas N.T.” (Donaire, 1991, p. 80), nas quais atua, respectivamente, como leitor do original, e autor da tradução. Essas fases se tornam evidentes nas N.T. porque nelas, segundo a autora, o tradutor-leitor fornece "chaves de leitura", e o tradutor-autor "chaves de tradução" do texto (id., p. 83). A partir desses conceitos, Donaire traça duas tipologias de notas: na primeira delas, o tradutor fornece chaves de leitura, e na outra oferece chaves de tradução.

As chaves de leitura podem ser:

1. Intervenções eruditas, isto é, informações que não são essenciais para a compreensão do texto e que não foram fornecidas pelo autor do texto original.

2. Conotações culturais ou linguísticas que, supostamente, o leitor do original conseguiria interpretar mesmo que não estejam no texto, mas não o leitor da tradução.

3. Conotações culturais ou linguísticas presentes no original que se perdem na tradução devido à não correspondência de conceitos e referenciais entre os sistemas 
linguístico-culturais do original e da tradução.

Em sua análise, a autora afirma que há uma gradação entre os três tipos de notas, sendo as últimas aquelas em que a intervenção do tradutor é menos discutível.

A tipologia de notas onde são oferecidas chaves de tradução, sempre segundo a autora, também tem três estágios (id., p. 88-90):

1. Notas que simplesmente informam o leitor da tradução sobre o fato de que um fragmento do original estava originalmente escrito na língua da tradução.

2. Notas que dão conta da perda de uma conotação, seja porque o tradutor não encontrou solução que a evitasse dentro do texto, seja porque a solução que encontrou implicava o empréstimo de um termo. O que conta, para este tipo, é a declaração das razões do tradutor para sua escolha.

3. Notas em que o tradutor informa sobre uma interpretação pessoal, sua, do original. A pesquisadora identifica este terceiro tipo com as intervenções eruditas mencionadas como tipo (1) das chaves de leitura, sendo que neste caso o tradutor se manifesta pela sua ótica de autor.

92 Embora a divisão de notas de leitura e notas de tradução pareça à primeira vista razoável, a tipologia proposta por Donaire não parece totalmente generalizável devido ao fato de que ambos os segmentos estão divididos por critérios diferentes: as notas de leitura percorrem um eixo que poderíamos denominar de "necessidade do leitor percebida pelo tradutor-leitor", enquanto que as chaves de tradução percorrem um eixo que poderia ser chamado de "problemas de traduzibilidade". Ou seja, o segundo eixo não envolve a noção de "necessidade", e o primeiro não envolve a de "traduzibilidade". Os exemplos também tornam claro que nem sempre se pode dizer definitivamente se uma nota dá uma chave de leitura ou uma chave de tradução, como se pode apreciar no exemplo dado para o terceiro tipo de notas de chaves de tradução, que envolvem uma interpretação:

Sirva de exemplo, novamente, Magia quotidiana. ${ }^{3}$ Na página 90 , o tradutor começa a propósito de "Uma prise, general?": "Pode-se supor que se trata (é claro que num imaginado anacronismo) de um convite para cheirar rapé ou mastigar tabaco (N.T.) (id., p. 90).

"Prise", em francês, referido a rapé é "dose, pitada" (Infopédia, "prise":9), daí a leitura do tradutor. O que caberia questionar aqui é: por que razão essa nota envolvendo uma interpretação é citada como uma chave de tradução, e não como uma chave de leitura?

Parece ser significativo que, mesmo havendo uma tentativa de descrição formal das notas, a pesquisadora se detenha a considerar sua eventual aceitabilidade, dando a sua 
contribuição um caráter híbrido: uma abordagem descritiva com algumas considerações prescritivas.

Jacqueline Henry (2000) oferece uma classificação das notas inseridas pelos tradutores franceses de um romance específico escrito em língua inglesa. ${ }^{4}$ Estas notas têm uma peculiaridade: na ficção do romance, um tradutor japonês fictício escreve cartas ou telegramas para seu autor inglês, também fictício, solicitando esclarecimentos semânticos sobre passagens de seu texto. No original, o tradutor escreve em inglês e cita as passagens em inglês. Os tradutores franceses do romance em questão, deixam em inglês as passagens do romance fictício objeto das indagações do tradutor japonês fictício, e colocam em nota a tradução das passagens para o francês, de forma tal que fiquem evidentes para o leitor as ambiguidades que originaram a consulta do tradutor ao autor dentro da ficção. Percebe-se claramente que a inserção das notas busca resolver os problemas oriundos de discussões sobre uma tradução intradiegética envolvendo a língua que o leitor da tradução do romance, a princípio, não conhece (pois é a língua de seu original).

A autora aborda também as copiosas e eruditas notas de uma edição shakespeareana bilíngue. ${ }^{5}$ Segundo a pesquisadora, tudo nessa edição, do formato bilíngue às notas, é testemunho de seu intuito notadamente pedagógico do tradutor, Aurélien Digeon, professor e pesquisador de literatura da Sorbonne.

Num estudo sobre N.T. não se poderia ignorar a contribuição de Solange Mittmann, que publicou o livro Notas do Tradutor e Processo Tradutório: Análise e Reflexão sob uma Perspectiva Discursiva (2003). Nesse trabalho, que utiliza a aparelhagem teórica da Análise do Discurso, a autora agrupa os posicionamentos teóricos de alguns autores em relação às notas em três categorias: 1. um "recurso para resolver problemas de tradução que não foram resolvidos no próprio texto" (id, p. 118); 2. um espaço que é parte integrante e inseparável da tradução e que, junto com esta, "é resultado de uma interpretação particular, que se dá em condições específicas e se dirige para um público diferente daquele imaginado pelo autor" (id, p. 120); 3. um espaço que o tradutor usa consciente e deliberadamente para expressar, às claras, "os problemas, as dificuldades, as angústias" que surgem da atividade de traduzir (id, p. 122). Assim, para a autora, há um continuum entre os três posicionamentos que vai de considerar o tradutor um mero transmissor e esclarecedor de conteúdos para um público de língua diferente àquela da "versão original" do texto, até um produtor consciente de uma leitura peculiar daquela versão, alguém que se manifesta livre e criativamente tanto no texto 
da tradução quanto nas N.T. A partir desta classificação, a autora defende as N.T. como "um lugar privilegiado para a análise de como se realiza o processo tradutório" (id, p. 131), que ainda que seja, para a autora, uma oportunidade de pesquisa em Análise do Discurso, é claramente um olhar que se poderia juntar às abordagens descritivas por conta do corpus utilizado.

Voltando às pesquisas em torno da tradução de textos sagrados, Rodrigo Gomes Ferreira escreveu uma dissertação (FERREIRA, 2006) em que analisa as notas dos tradutores de 8 versões da Bhagavad-Gītā em português. Ele oferece três possíveis leituras do texto enquanto texto literário, enquanto texto religioso e enquanto texto filosófico - e parte do pressuposto de que as N.T. refletirão uma dentre essas leituras. O corpus é composto de cerca de 1600 N.T., sendo que $76 \%$ do total pertencem a apenas duas delas, e através de uma abordagem descritiva ele as classifica segundo seu conteúdo: por trazerem referências, remissões intratextuais, explicações, etc.

A variedade e quantidade de anotações, bem como as desigualdades do corpus, são sinal da complexidade e da variedade de abordagens do texto traduzido.

94 Na mesma área, mas com um enfoque diferente, comentarei a seguir um artigo recente que lida com a tradução do Alcorão para o espanhol.

Ahmed Kamal Zaghloul (2011) analisa as N.T. de sete traduções do Alcorão. O pesquisador também demonstra ter um olhar prescritivo sobre as notas, defendendo a inclusão das de caráter exegético em virtude da distância histórica, linguística e cultural entre os leitores atuais e aqueles que escreveram o Livro Sagrado (id., p. 28).

Mas essa postura prescritiva também parte de uma visão crítica, engajada e decorrente de uma abordagem descritiva. Zaghloul afirma que, em primeiro lugar, tradutores árabemuçulmanos do Alcorão inserem, visivelmente, muitas mais notas do que os europeus (dentre os quais ele cita três cristãos, um judeu e um ateu), o que, segundo ele, está relacionado com a crença deles no caráter inimitável do Livro Sagrado (id., p. 29). Em segundo lugar, ele assinala outra característica comum a todos os tradutores, a tentativa de relacionar em suas notas os versículos do Alcorão (ayat) com os versículos bíblicos, embora em comentários de teor muito diferente: enquanto os não-muçulmanos, segundo o autor, buscam enfatizar a influência das Escrituras judaico-cristãs no Alcorão, os muçulmanos o fazem para reforçar a visão de que o Alcorão, assim como a Bíblia, é uma revelação divina. Outras observações na mesma linha se seguem: tradutores muçulmanos exaltando as virtudes do Livro Sagrado, não- 
muçulmanos denunciando contradições entre os versículos, ou muçulmanos se referindo a Maomé como voz do Alcorão, não-muçulmanos colocando sob suspeição a autenticidade de alguns versículos, e assim por diante. Em outras palavras, o pesquisador realça o proselitismo militante dos tradutores do Alcorão, seja a favor ou contrário, que encontra nas notas um terreno fértil para se manifestar. Na conclusão do artigo, o pesquisador explicita seu intuito normativo:

Ao transmitirem livros sagrados para outras línguas, os tradutores deveriam demonstrar a máxima objetividade e fidelidade possível. O tradutor que pretender ser invisível diante dos leitores do texto terminal, deveria oferecer a opção para que eles possam refletir sobre o que leem, e não aproveitar as notas de rodapé para criticar ou defender o livro objeto de tradução (id., p. 35).

Para concluir, comentarei o trabalho de Marie-Hélène Torres, Para traduzir o Brasil literário (2014), que, com base na aparelhagem teórica dos estudos descritivos da tradução, constitui uma aprofundada análise de traduções brasileiras publicadas na França que a partir das notas dos tradutores lhe permite, por exemplo, rastrear a interpretação do texto pelos tradutores (p. 95), identificar a estratégia de tradução (passim), e mostrar de forma muito clara que em traduções de best sellers as N.T. não são tratadas da mesma forma que em traduções de autores do cânone da literatura brasileira, como por exemplo Machado de Assis: nos primeiros, as notas tendem a não existir, enquanto que nos segundos há vários exemplos de profusão de N.T. O amplo estudo de Torres contrasta com o fato de que Venuti tenha deixado praticamente de lado as notas no seu estudo.

Estas são algumas contribuições sobre N.T. feitas por estudiosos desde os anos 1960, quando efetivamente começaram a aparecer com alguma frequência, até os dias de hoje. Cabe frisar que há outras contribuições, mas não em grande número. Creio que é bastante visível o impulso que o pensamento sobre tradução deu às contribuições sobre N.T. De contribuições iniciais exclusivamente prescritivas, o desenvolvimento dos Estudos Descritivos da Tradução permitiu o surgimento de contribuições descritivas e críticas, e mesmo as contribuições prescritivas recentes parecem ter adquirido uma feição mais metódica pela busca de uma base em traduções reais.

\section{Bibliografia}

CARDELLINO Soto, Pablo (2011). Traducción comentada de "O espelho", de Machado de Assis, al español. Florianópolis, 2011. Dissertação (Mestrado em Estudos da Tradução) Universidade Federal de Santa Catarina, Florianópolis. 148 p. Orientador, Walter Carlos Costa; co-orientador, John Gledson. 
DONAIRE Fernández, M. ${ }^{a}$ Luisa (1991). “(N. del T.): Opacidad lingüística, idiosincrasia cultural". In: $\mathrm{M}^{\mathrm{a}}$ Luisa Donaire \& Francisco Lafarga (ed.). Traducción y adaptación cultural: España-Francia. [Oviedo, España]: Universidad de Oviedo, Servicio de Publicaciones, pp. 79-91.

FERREIRA, Rodrigo Gomes (2006). Análise das notas de tradução em edições brasileiras da Bhagavad-Gītā. Florianópolis: Universidade Federal de Santa Catarina. Dissertação de Mestrado em Estudos da Tradução. 371 pp.

HENRY, Jacqueline (2000). De l'érudition à l'échec : la note du traducteur. Meta, vol. 45, $\mathrm{n}^{\circ} 2$, p. $228-240$.

INFOPÉDIA. Dicionário de Francês-Português. [s.1.]: Porto Editora. Disponível em <http://www.infopedia.pt/frances-portugues/>. Acesso em: 2 fev. 2014.

NEWMARK, Peter (1987). A textbook of translation. New York / London / Sidney / Toronto / Tokio: Prentice Hall.

NIDA, Eugene A (1964). Toward a Science of Translating: With Special Reference to Principles and Procedures Involved in Bible Translating. Leiden (Países Baixos): E. J. Brill.

NIDA, Eugene; TABER, Charles R (1982). The Theory and Practice of Translation. 96 Leiden: E. J. Brill.

RÓNAI, Paulo (1976). A Tradução vivida. Rio de Janeiro: Educom.

TORRES, Marie-Hélène Catherine. Para traduzir o Brasil Literário: história e crítica. $1^{\mathrm{a}}$. ed. Florianópolis: PGET/UFSC; Tubarão: Copiart, 2014. 397 p.

VENUTI, Lawrence. The Translator's Invisibility. Londres: Routledge, 1995.

ZAGHLOUL, Ahmed Kamal (2010). Las notas a pie de página en la traducción del Corán. Entreculturas, n. 3., II semestre de 2010 (data de publicação: 12 jan. 2011), pp. 1726. Granada (España): Comares Editorial. ISSN: 1989-5097.

\footnotetext{
${ }^{1}$ Pablo Cardellino Soto. Disponível em: http://lattes.cnpq.br/6792297035986201

2 Doravante, "N.T.".

${ }^{3}$ A pesquisadora se refere a Magia cotidiana, de André Breton, publicado em Madri pela Fundamentos, em tradução de Consuelo Berges, que foi quem teve o nome estampado na quarta-capa com carimbo de borracha. Aparentemente, o livro permanece inédito em português.

${ }^{4}$ Lodge, David (1985). Small World. Penguin Books. Tradução de Maurice et Yvonne Couturier (1991): Un tout petit monde, Paris, Rivages.

${ }^{5}$ Shakespeare, William (1969) : Troilus and Cressida/Troïlus et Cressida, éd. bil. Aubier-Flammarion, Paris, Aubier. Traduit par M. Aurélien Digeon.
}

RECEBIDO EM: 30/11/2014

ACEITO EM: 05/08/2015 